\title{
Early modern Oxford bindings in twenty- first century markup
}

Article

Accepted Version

McCarthy, E., Wheale, S. and Welsh, A. (2012) Early modern Oxford bindings in twenty-first century markup. Library Review, 61 (8/9). pp. 561-576. ISSN 0024-2535 doi:

https://doi.org/10.1108/00242531211292079 Available at https://centaur.reading.ac.uk/34876/

It is advisable to refer to the publisher's version if you intend to cite from the work. See Guidance on citing.

Published version at: http://dx.doi.org/10.1108/00242531211292079

To link to this article DOI: http://dx.doi.org/10.1108/00242531211292079

Publisher: Emerald

Publisher statement: This article is (c) Emerald Group Publishing and permission has been granted for this version to appear here (http://centaur.reading.ac.uk/). Emerald does not grant permission for this article to be further copied/distributed or hosted elsewhere without the express permission from Emerald Group Publishing Limited.

All outputs in CentAUR are protected by Intellectual Property Rights law, including copyright law. Copyright and IPR is retained by the creators or other copyright holders. Terms and conditions for use of this material are defined in the End User Agreement. 


\section{CentAUR}

Central Archive at the University of Reading

Reading's research outputs online 
Title:

Early modern Oxford bindings in twenty-first century markup

Authors:

Elizabeth McCarthy (Communications and Special Collections, Bodleian Libraries, Oxford, UK) Anne Welsh (Department of Information Studies, University College London, London, UK)

Sarah Wheale (Rare Books, Bodleian Library, Oxford, UK)

\section{Structured Abstract:}

Purpose: The Bodleian Binders Book contains nearly 150 pages of 17 th-century library records, revealing information about the binders used by the library and the thousands of bindings they produced. This paper explores a pilot project to survey and record bindings information contained in the Binders Book.

Design/methodology/approach: A sample size of seven pages (91 works, 65 identifiable bindings) to develop a methodology for surveying and recording bindings listed in the manuscript. To create a successful product that would be useful to bindings researchers, it addressed questions of bindings terminology and the role of the library in the knowledge creation process within the context that text encoding is changing the landscape of library functions. Text encoding formats were examined, and a basic TEI (Text Encoding Initiative) transcription was produced. This facilitates tagging of names and titles and the display of transcriptions with text images.

Findings: Encoding was found not only to make the manuscript content more accessible, but to allow for the construction of new knowledge: characteristic Oxford binding traits were revealed and bindings were matched to binders. Plans for added functionality were formed.

Originality/value: This research presents a 'big picture' analysis of Oxford bindings as a result of text encoding and the foundation for qualitative and statistical analysis. It exemplifies the benefits of interdisciplinary methods - in this case from Digital Humanities - to enhance access to and interpretation of specialist materials and the library's provenance record.

Published article DOI: $\underline{\text { http://dx.doi.org/10.1108/00242531211292079 }}$

Originally published: Elizabeth McCarthy, Anne Welsh, Sarah Wheale, (2012),"Early modern Oxford bindings in twenty-first century markup", Library Review, Vol. 61 Iss: 8 pp. 561 - 576.

This article is (c) Emerald Group Publishing and permission has been granted for this version to appear here (http://centaur.reading.ac.uk/). Emerald does not grant permission for this article to be further copied/distributed or hosted elsewhere without the express permission from Emerald Group Publishing Limited. 


\section{Introduction}

This article reports the findings of a project piloting the use of markup language for the Bodleian Library's Binder's Book (BB) - a manuscript volume documenting the books sent by the Librarian to local binders, complete with notes on their physical condition and imperfections. Covering the period 1621-24, it provides a means of pinpointing the existence in the Library of the books it lists, and so is an important resource for provenance research. Yet it goes beyond enumerating book stock; it offers a glimpse into library management in the Early Modern period, valuable provenance information and an opportunity to make data on library materials useable.

The search capabilities afforded by the creation of an electronic version of the $B B$ were drivers behind the project. However, the textual encoding of an entire manuscript is beyond the expectations of the day-to-day role of a rare books librarian. Framed as a graduate project by a member of staff undertaking courses in Library \& Information Studies, it was possible to create a pilot resource, demonstrating the potential benefits of a wider project. This facilitated an opportunity to investigate the different options for textual encoding, before bringing the project back in-house for evaluation and further development.

The project exists at the nexus of three disciplines: Librarianship; Bibliography; and Digital Humanities (utilising computing in the pursuit of Humanities research). Because the $B B$ is an archival document, it may also be of interest to the archive world. Clearly, the $B B$ itself has a provenance, but this project is concerned with its contents. It joins a growing list of library projects using the opensource standard developed by the Text Encoding Initiative to provide access to heritage resources.

The current article provides an overview of the steps taken to create a working version of the $B B$ in TEI (an html sample of which can be found at http://www.ucl.ac.uk/ uczcega). A brief survey of literature on Oxford bindings and textual encoding in the Digital Humanities is followed by a detailed project description. Its nature as a pilot means that the focus of the article is methodological, covering encoding schema and bindings terminology, although the outcomes are entirely practical - a working searchable resource for those with an interest in bindings, currently populated by sixty-five bindings records transcribed from the $B B$. The article concludes that, the pilot stage having ended, the Bodleian is now in a strong position to bring the $B B$ in TEI back in-house in the interests of sustainability and data sharing (within the Bodleian and, if appropriate, with other binding documentation projects). Finally, this project is offered as an example of the kind of work that can be undertaken by library employees as part of their graduate studies, which allows for innovation and the incorporation of new research methodologies within traditional library projects.

\section{Oxford and the Binder's Book}

Although Oxford was not the binding centre that London proved to be, the University gave rise to industries surrounding book production. Manuscript production had thrived in Oxford for centuries; Parkes notes a 'flourishing book trade' by 1210 (2008) and Gibson identifies over 70 bookbinders working between 1180 and 1636 (1903). Printing began to augment scribal work in Oxford in the late 1470 s, and throughout the following century a variety of fine binding work was produced for college libraries. After the opening of the Bodleian, the Library's presence on the binding scene slowly grew. Bodley originally used London binders for the majority of the Library's needs, being distrustful of local craftsmen (Philip, 1983); after his death in 1613, however, local binders began to play a more significant role. It is unclear what proportion of stock was purchased unbound, which makes an analysis of the financial costs of bindings difficult; one of the long-term goals of the ongoing project will be to answer these questions.

The BB's principal use thus far has been to identify and reclaim the Bodleian's original copy of Shakespeare's First Folio. The volume was sold in the seventeenth century, presumably as part of "a packet of 'superfluous Library books' sold in 1664" (Craster, 1952); when it resurfaced in 1905, librarians were able to match waste paper to other bindings from the same $B B$ entry and prove its provenance. Yet the $B B$ provides more: unique historical insight into the practical workings of the seventeenth-century Bodleian, as well as the opportunity to study and place library bindings on an enormous scale. The BB, labeled 'Day Book 1621-1624' on the spine, is a simple vellum-bound notebook in which the Library recorded the receipt of these books. It is the second of seven day books, 
but one of only two from the seventeenth century. Its 78 leaves (plus pastedowns) include the names and signatures of fourteen (possibly fifteen) binders, two booksellers, hundreds of authors, and over 1,000 works. Written principally by under-librarian Jean Verneuil, the volume notes which binder dealt with a book and the condition in which it returned. The entries specify books bound together and occasionally give additional information, such as number of volumes, size, price and snippets such as noting "to be changed being spilt by the Cariage" ( $B B, f .37 \mathrm{r})$. Most of these works remain in the Bodleian and can be matched to their $B B$ entry, called up and examined.

The $B B$ thus offers a good partial representation of what an academic library possessed. It is clear that Bodley took interest in the day-to-day workings of his library; his letters to Librarian Thomas James are full of queries about individual books and projects (Bodley, 1703). His care - and that of his staff - in recording library data allows definitive matching of bindings and binders on a large scale, using information gained to add insight to the workings of both the Library and the book trade in Oxford.

\section{Studying bindings}

Traditional surveys of English bindings in Oxford were thorough. Brassington published one of the first works in 1891. Strickland Gibson's output $(1900,1901,1903,1907)$ addressed not only bindings but also binders and the traces they left. Combined with Ker's work on Oxford pastedowns (2004) and histories of the University and Library by Madan (1895), Macray (1890) and Philip (1983), Gibson's surveys are invaluable for identifying names, tools and background, particularly placed in the broader context of similar English surveys by Oldham (1952), Hobson (1929a, b) and Pollard (1955). Although subsequent researchers have added to the Oxford corpus, most have merely selected fine bindings to display.

In a digital world, however, it becomes difficult to discuss bindings without discussing how to discuss them, particularly as online surveys are more likely to require consistent or controlled vocabularies. As Pearson put it, "It is a regular refrain ... that we are hampered by the lack of a widely accepted standard vocabulary for describing the features of historic bindings" (2005). Take the following examples. The RBMS Controlled Vocabularies: Binding Terms (1988) encourages the use of the term 'decorated edges' for treatment of text block edges. Roberts and Etherington (1982) suggest edge decoration but give eighteen further references; the Getty Art and Architecture Thesaurus (2000) has also adopted that term. Miller's extensive vocabulary describes not only 'edge treatment', but also two primary and fourteen secondary types (2010) - and the list goes on. Terminology seems to have become one of the biggest hurdles in designing a bindings study that will speak not only to the bindings community, but also to an interdisciplinary academic world - and in an age of Digital Humanities, the ability to link up is crucial. Indeed, terminology is now one of the focal points of most current studies.

Current studies are often large-scale bindings surveys that aim to compile as much data as possible for processing. Ligatus has been working on approximately 3,300 manuscript and 1,000 printed book bindings at St Catherine's Monastery (Ligatus, n.d.b.); the Census of Medieval Bindings has examined over 14,000 bindings since 1989 (Digital Preservation Europe, 2006-07); the British Library's Database of Bookbindings provides a search interface for over 6,000 bindings (Goldfinch, 2011); ProBok aims to provide a complete survey of early Swedish bookbindings (ProBok, 2010-11); Einbanddatenbank includes 68,000 records (Wittenberg, 2011); MEI places bindings information in the context of other provenance data (Dondi 2011); the Folger Bindings Images Collection, though launched after the bulk of this study, provides another access point to hundreds of bindings (Folger 2012). Many of these projects have addressed vocabulary; one aspect of the Ligatus project seeks to confront the issue by creating a "definitive" bookbinding glossary to combat the "complex combination of traditional trade terms and descriptions compiled by antiquarian booksellers and rarebook cataloguers" (Ligatus, n.d.a \& n.d.b). Miller highlights the American Institute for Conservation Book and Paper Group's work on a "process-specific, illustrated outline of historical bookbinding practice" which will establish terminologies (2010), and ProBok (n.d.) aims to establish "a controlled vocabulary ... [that] comprises all terms needed to describe the basic type, material and specific traits of the binding." These surveys and their linguistics represent an important segment of the work of the modern bindings historian - in part because, for the first time, this volume of information can actually 
be useful, but also because there is now an academic appreciation of the historical stories that bindings can reveal.

\section{Encoding and the Digital Humanities}

How to reveal these stories is also an important question. The definition of Digital Humanities continues to evolve, and a large proportion of literature - enough that Kirschenbaum believes they are "already genre pieces" (2010) - seeks to justify the role of markup in the Humanities.

Academic literature dates back to the earliest days of markup and follows a theoretical discussion of its role - for instance, the conversations surrounding Renear's exploration of the nature of text (DeRose et al., 1990; Renear et al., 1996; Renear, 1997). Encoding projects are still determining the most efficient way of dealing with bindings records; it is not yet clear that there is a markup language that expresses them adequately. What Renear's concept of anti-realism does make clear is that textual projects must understand that their work inevitably "exercise[s] rhetorical and ideological force" upon texts (Drucker, 2009). Text encoders should act with the awareness that they impose meaning upon texts, rather than merely presenting them for others (McGann, 2001). This can be problematic when the document expressed is technically archival in nature, as the BB. The archive world has developed EAD (Encoded Archival Description) for finding aids; it has its own system for allowing interpretation by the encoder, but the world of textual encoding has no similarly evidential language. As one of the first in Oxford to bring together manuscript records and binding metadata through XML encoding, this project aims to contribute to a growing discussion of the best way to describe such information.

Although TEI is one of the most widely used markup languages, it is not without criticisms, especially in the case of binding expression and analytical bibliography; its structures were originally designed "to represent intellectual structures ... the representation of the physical structures of the document containing the text are usually subordinated to the representation of the logical structures" (Bauman and Catapano, 1999). Similar projects have thus chosen different routes. MEI (Material Evidence in Incunabula) chose a simple Unimarc format with SRU (the Search/Retrieve by URL protocol) capabilities (Dondi, 2011). Ligatus, whose survey has been one of the most detailed, states that it will not use TEI, but a related XML schema (Velios, 2011). Others have expressed concern at the concept of coding a text in a way that "assume[s] that a document is a single hierarchic structure" (Hockey, 2000) and are wary of the inherent structural requirements of a format like TEI. Schmidt (2010) cites this concern as one of four serious issues with using TEI to mark up cultural heritage.

TEI is inherently flexible and can cater for multiple formats; as TEI@Oxford (2011) points out, "Many other standards exist and the TEI has tried not to reinvent the wheel ... instead allowing you to embed markup from other vocabularies in your TEI document where necessary." It allows the simultaneous encoding of multiple hierarchical embodiments of a manuscript - in this case, of the manuscript text itself and the metadata that the related bindings can relate. It allows for different 'levels' of encoding, depending on the scholarly needs of the project and the level of analysis it wishes to reflect. The TEI community is a robust one, particularly in Oxford, with strong support for TEI use in the Digital Humanities.

\section{Methodological concerns}

Previous bindings surveys and encoding projects are so varied that they both provide ample guidance and make it difficult to know where to start. The $B B$, though only seventy-eight leaves, lists significantly more than 1,000 works. The material is connected to at least fifteen individuals in the binding and bookselling world as well as thousands of bibliographical records. Deciding how to turn this information into something meaningful was not straightforward.

\subsection{Transcription and searcbing}

The contents of the book needed to be accessed, and the only way to do that was direct transcription; as John Lavignino (2006) remarked, "To use the TEI approach you need to believe in transcription." Early handwriting's irregularity does not suit optical character recognition; all work was done with a pencil, paper and laptop. Parts of the transcription had been completed over the previous two years; 
transcription issues were those common to scholarly projects and involved basic information formatting and conundrums of legibility. Primary author Verneuil's hand is neat and regular, only occasionally posing significant barriers. Questions of transcription style - i vs. j, symbols, etc. - were usually addressed according to the general guidelines set out in Appendix G of the Library of Congress/RBMS's Descriptive Cataloging of Rare Materials (Books) (2007) as well as basic reference texts such as Petti (1977, Hector (1980), Parkes (1979) and Harvey (2001). Expansions and other visual features were noted. As the project was still in germination while transcription was beginning, decisions erred on the side of completeness; the goal was to represent information in a format that would not limit its future uses.

Hand transcription and photographs kept an accurate visual record of page formatting. Information was transferred to spreadsheets, which provided basic searching and sorting functionality. Each work listed in the $B B$ was searched in the Bodleian Libraries' catalogues and matched to a Bodleian copy (where extant).

\subsection{Bindings survey}

The result of the initial transcription stage was a series of spreadsheets representing binders and shelfmarks. The next obvious step was to look at the bindings themselves. This pilot project allowed neither the time nor the discussion space to look at every book listed in the $B B$, so a manageable sample had to be selected. A random selection of approximately thirty-five titles was examined first in order to determine which types of bindings features remained intact as well as whether the initial shelfmark matching had been accurate. These preliminary examinations showed that the majority of bindings were still intact and traceable; it appeared that each binder's work was relatively consistent within a limited range of styles and could be identified at least tentatively.

\subsection{Survey points}

This preliminary stage was necessary to determine the sort of information the bindings offered and how best to craft a survey that would reflect that information. It involved regular changes to an initial list of information to record. Miller's chapters on describing bindings and survey samples provided an excellent starting point, suggesting the following items for a barebones survey (2010):

- Reference citation

- Measurements

- Contemporary/non-contemporary binding

- Cover materials

- Cover decoration

- Edge decoration

- Spine type and decoration

- Titling

- Style

- Visible structure

- Sewing/attachment style

- Cover-to-text attachment style

- Endband style

- Endpaper material

- Text block material

- Information bound in

- Identifying marks and inclusions

- Notes

- Documentation

Pickwoad's Ligatus “Assessment Manual” (2004) and the Census of Medieval Binding's survey form (British Census Project and Sheppard, 1997) provided additional points for a standard survey, which were modified by comparing information presented by other bindings survey projects, including 
CERL's Material Evidence in Incunabula (http://www.cerl.org/en/resources/mei/main) database and the British Library's Database of Bookbindings.

In consultation with Bodleian bindings conservators and rare book curators, a set of survey points was developed that would provide adequate information for differentiating Oxford bindings and binders. Terminology was chosen to ensure maximum correlation with other mainstream projects and reference tools such as the ESTC (http://estc.bl.uk/) and binding projects such as those listed above. Bindings information was matched with bibliographic data from the Bodleian Libraries catalogue, data from the $B B$ and outside references to tools or works where relevant (for example, the Bodleian Incunabula Catalogue [Coates et al., 2005]).

Reference points could not be unlimited. The Ligatus survey required a ten-page document and at minimum an hour for each volume (Velios, 2011). Future project sustainability may not allow the funding, time and knowledge needed for such minute detail. Key elements were recorded, from the very basic - material and decoration - to the particular - watermark and basic sewing style - but other elements were determined too specialist for a researcher with moderate bindings knowledge to identify. Excluded elements included styles of endpaper attachments, endband sewing styles, etc. - those "structural features which may only be apparent once a book is taken apart on the conservator's bench" and which "cannot, for most practical purposes, become mandatory prerequisites for binding elucidation" (Pearson, 2005).

\subsection{Sample size}

A sample size of seven non-consecutive pages was chosen, representing just under $10 \%$ of the manuscript. True probability sampling was neither feasible nor desirable; the project needed a purposive sample that would encompass multiple binders and a variety of languages, publishing origins and material type as well as the additional information included in some parts of the manuscript (price, imperfections). The average number of page entries varied, but a total of ninety-one works and sixtyfive bindings were represented. Clearly, a sample is inherently flawed in that it cannot possibly reflect every eventuality. However, this sample's purpose was to address each type of information contained in the manuscript, determining patterns in binding styles that would differentiate binders and how best to present the information in a digital format.

\subsection{Encoding}

The binding survey itself generated relevant information about Oxford bindings and binders in the seventeenth century, how to identify them, and how the Bodleian Library dealt with bindings, but the results are of more use as part of a larger corpus. The second phase of the project used TEI encoding to turn $B B$ data into something that could be accessed without having to reconstruct the survey. XML markup standards provide methods of presenting the $B B$ and additional metadata gleaned from the bindings survey; they also play "an important part in the process in the long-term preservation, enhanced access, and dissemination" of texts (Wisneski and Dressler, 2009).

The second part of the project, then, was to create a TEI edition of the $B B$ sample, providing visual commentary via the option of manuscript images alongside transcribed textual records and added metadata relating to its contents. Sample documents produced by the University of Oxford were examined for best practice (for example, the Shakespeare Quartos Project [www.quartos.org] and Best Practices for TEI in Libraries [TEI Consortium, 2009]); it was clear that the encoding needed the use of the elements ascribed to manuscript description (<choice $>,<$ corr $>$, etc.) as well as sophisticated search functions, which may be required of the encoding from researchers looking for particular references. The result relied heavily on TEI's $<$ msDesc $>$ and $<$ facsimile $>$ elements, which are designed for digital editions and allow not only contents expression but also physical and historical description for a given manuscript, allowing the expression of the $B B$ as an important archival record (TEI@Oxford, 2010). BB 'entries' (a title/binding entry or administrative note) were favoured structurally over line breaks (lb/>) by using $<\mathrm{ab}>$ to contain each item; this will facilitate later links to binding information via unique identifier. Individual titles and authors or binders were specified using $<$ title $>$ and < persName $>$; these can also be given unique identifiers and linked to either catalogue entries or an external database. 


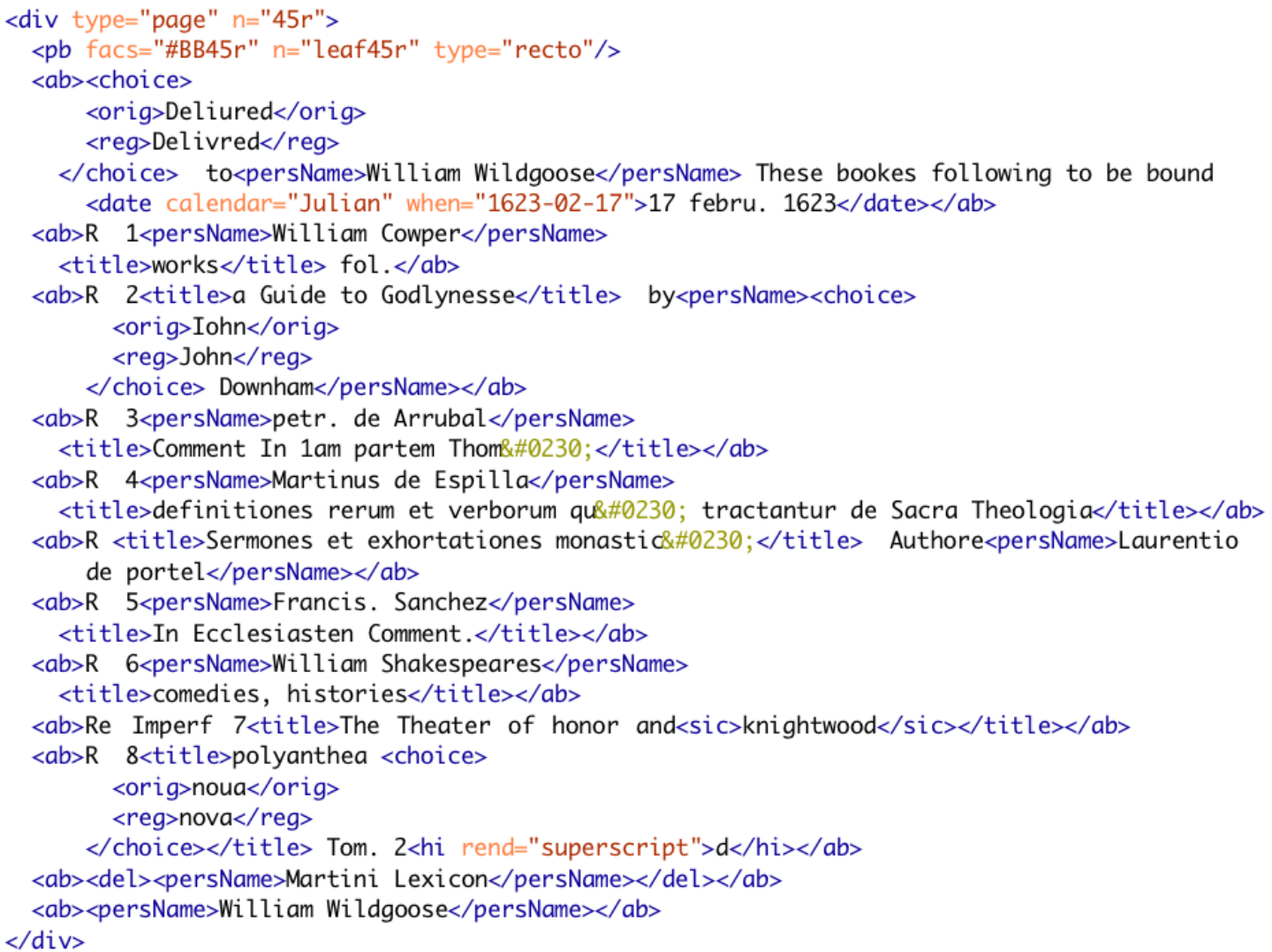

Figure 1: Folio 45r of the Binder's Book in TEI

The resulting resource provides a complete transcription of the seven project sample pages, with additional linking and tagging such as names, places, titles and shelfmarks where written in the text. It provides rough facsimile images of the text, to be read alongside the transcription. Various advanced transcription elements have been catered for, including some regularisation options (e.g. i/j), and the resource is set up to provide links to shelfmarks and binding information for each item.

All this is achievable for the beginning encoder or project with limited funding, but it leaves enormous scope for development. What the resource does not yet do - but can in the future - is provide a direct link from each entry to a full bindings record. It has the potential to provide basic search as well as links to catalogue records like those of the Bodleian or MEI and other CERL databases, as well as providing options for alternate spelling searches. It can become a powerful tool with connections to other similar resources.

\subsection{Next steps}

The great advantage of running a whole project methodology on a pilot sample is the opportunity to improve it. The survey strategy was derived from numerous similar projects. One of its key factors was sustainability; the project is currently designed as a one- or two-person job. It would be beneficial to develop a standardised method of collecting information, rather than just a consistent vocabulary. After initial design work, an online record would automate the encoding process, allowing bibliographical records to be imported. It would allow simpler ways of linking material bound together and matching $B B$ material that appears more than once, and it would reduce human error and differences in vocabulary, spelling, etc. It could also facilitate the addition of other metadata standards; for example, the use of METS (Metadata Encoding and Transmission Standard:

http://www.loc.gov/standards/mets/) to manage associated images, as suggested by Wisneski and Dressler (2009). One of the advantages of the project's scope as a one-person pilot is that while innovation has been allowed free rein in order to formulate a markup based on the needs of the manuscript itself, discussions can now take place within the wider framework of the Library's recent upgrade to Aleph (http://www.exlibrisgroup.com/category/Aleph). The next stages will certainly 
involve adapting the methodology into something appropriate for over a thousand volumes, but the project lends itself to other potential developments - turning the manuscript content or citations into downloadable records, ensuring that the Bodleian catalogue is updated with the information gleaned and, most importantly, using the data to find out more about library processes.

\section{Bindings analysis}

The survey sample was designed to determine how much evidence of early Oxford binders could be gleaned by comparing library records to the books themselves. In fact a great deal was revealed; although not all binding characteristics are unique to their binders, elements help place Bodleian bindings known to be original to the Library. In addition, it became clear how the Library treated particular kinds of publications - English and foreign, for instance, or pamphlets and full volumes.

\subsection{People and places}

The first step was to identify each of the binders in the sample. Strickland Gibson conveniently provides lists of Bodleian binders (and their dates) in Early Oxford Bindings (1903). The sample included seven of the full $B B$ list of fourteen (or fifteen, depending on a spelling variant), as well as entries referencing Mr. Featherstone, who was the Library's chief London supplier from 1621 (Philip, 1983). A Mr. Badger is also mentioned on folio 70v (12 April 1623); Philip (1983) indicates that Badger's books were the Library's 1623 Stationers' Company intake.

The bindings were recorded in the $B B$ over the period 1621-1624. The most common months for entries are February, August and October/November, which may reflect the dates of the spring and autumn book fairs. The material's publication dates represent a significant span. Books of similar dates were not always bound together; Bodley often bound books without much concern for order:

In order to save binding costs and to cut down the number of fittings 'that the multiplicitie of cheines might take away the sight and shewe of the bookes,' Bodley increasingly had several books bound together ... without reference to any alphabetical arrangement (Philip, 1983, quoting Wheeler, 1926).

It is also clear that he rarely considered location or subject; although $4^{\circ} \mathrm{W} 10 \mathrm{Th}$. contains six works published in London in 1623, G 1.7 Jur. contains two works, one published in 1620 in Rome and one in 1577 in Leiden. This spread of locations is common, though the United Kingdom (primarily London, occasionally Oxford or Scotland) and Germany dominate. Entry language varies: English and Latin are the most common, but others in the sample included French, Greek and Italian.

\subsection{Structure and decoration}

Binding information was recorded in twenty-one categories, divided into basic information (status and date of binding, surmised binder), structure and material (covering, boards, sewing, binding and structural notes such as ties, supports, endbands, pastedowns, etc), decoration (boards, edges, spine, fore edge), provenance marks and labelling (shelfmarks, titling, binders' inscriptions, other inscriptions, former shelfmarks) and other references (Gibson's roll numbers, other). An impressively high proportion of the bindings was intact - an advantage in determining original features. Of more than seventy bindings, only three were clearly non-contemporary. Two of these were later eighteenthcentury Bodleian bindings (quarter calf with marbled paper or green cloth). One was modern; $8^{\circ} \mathrm{D}$ 15(7) Art. (BB f. 70r) was re-bound with particular care in 1988. On rebound volumes, residual evidence - such as original fragments preserved by the conservator - sometimes helped to identify former characteristics.

A further fifteen bindings had been repaired. This does not include simple pastedown repairs, which did not affect an ability to record the binding in the same way as strengthened sewings or full rebacking. Certain binders' works seemed to have been repaired in total; William Johnson's bindings, found on folio $21 \mathrm{r}$, had all been rebacked in a similar style. It is difficult to know precisely when most repairs were made; extensive work was sometimes accompanied by initials or date, so it may be possible at a future date to match conservation records with bindings.

Of the contemporary bindings examined, thirty-nine were calf and twenty-two vellum. Brassington noted in 1894 that "Oxford binding, though well finished and of great solidity, was not 
conspicuously artistic" and used "the old English manner." Pearson (2005) likewise notes a shift to plainer, blind-tooled fillet borders on books "bound in London according to Bodley's instructions" in about 1600 . Ker believes this shift began earlier, noting that by the later sixteenth century, roll bindings began to settle into rectangular shapes and the use of small ornaments was avoided - possibly as they "were beginning to look old-fashioned ... and some of them were wearing out" (2004). As expected, then, most volumes were consistent with plainer bindings of the time and boasted only blind tooling. This represents a contrast to locations such as London, where gold tooling and centre ornaments were more common (Nixon and Foot, 1992).

\subsubsection{Binding features}

Gibson (1903) notes that "parchment was largely employed after 1600 for small books," and the vellum-bound material was without exception quarto size or smaller and always limp. The sample's vellum-bound books had yapp edges, not common in cheap bindings elsewhere (Miller, 2010; Roberts and Etherington, 1982). They often lacked endbands and invariably had remnants of leather or occasionally linen ties; Middleton (1996) notes this as unusual on "ordinary bindings of the period." All had flat spines and many had hollow backs, as is common (Middleton, 1996); most had plain pastedowns.

The calf leather bindings were also simple, with variation in details such as the use of edge hatching or fillet placement. They were split between smooth, dark brown calf over pasteboard and reverse calf, favouring the latter and spread inconsistently among the binders. Ker (2004) noted that "rough calf became popular for Oxford bindings and did not provide an effective surface for applied decoration." Gibson agreed: "Rough calf is common from about 1620 ... most of the bindings in this leather are plain" (1903). As might be expected, then, all board decoration in original bindings was blind tooled, although edge work was often simple gold fillets. The BB thus both corroborates Gibson's work and links specific features with binders. The use of lines and edge rolls, for instance, differed by binder. Wildegoose generally used a four-line fillet, and the others three-line fillets - with occasional single lines and at least one triple-fillet surrounding a blind-tooled centre panel (B 17.14 Linc.) (Gibson, 1903). BB 49 Art. uses Ker's Roll XXIV, which had passed to Billingsley (Ker, 2004). Billingsley regularly used a simple edge pattern with lozenges alternately solid and bordered gold.

Gibson also noted the use of hatched lines on board edges near the spine as a particular Oxford feature (1903). Wildegoose, Bluett and Allam all used similar hatching, usually a few diagonal marks nearer the spine followed by a number of straight ones. Hatch marks ranged from two or four straight hatches in Billingsley and Wildegoose bindings to four to six straight and/or diagonal in the case of Johnson (G 5.13,14 Th.) and six to eight for Henry Bluett (BB 60 Art.). Wildegoose and Bluett commonly hatched the top and bottom spine edges as well, and Billingsley and Allam occasionally hatched raised bands.

Although Gibson notes that spine hatching was less common after 1620 (1903), Wildegoose clearly continued to use it (see C 12.9 Linc.) - usually diagonally on the top and bottom spine. Other spine decoration was limited almost entirely to blind-tooled lines alongside raised bands. Nearly all the calf bindings had raised single bands (usually four), remnants of two pairs of linen ties (despite Gibson's note that clasps were "in general use" [1903]) and library chains on the fore edge of the front cover, indicating shelving placement.

Edges were often coloured; most show evidence of being coloured after binding (presumably indicating that the binder did the inking). Gibson notes that red, yellow and ochre were the most common colours (1903); Pearson's wider-reaching survey (2005) suggests red overtook yellow in the seventeenth century, and that it was at this point that marking different works in one volume with varying decoration first emerged. Although vellum $B B$ bindings rarely boast edge decoration, the calfbound texts nearly always do. Red is most common, with two using only yellow and six using both at once. Two bindings used blue, and two ochre in addition to red and/or yellow. Billingsley often sprinkled or striped the text block, and Wildegoose usually used more than one colour. 


\subsubsection{Pastedowns and other information}

Oxford pastedowns have been examined at some length by Ker, but his work did not extend to the $B B$ volumes. Most are relatively uninteresting, but they do help date material and match bindings to binders. For instance, certain kinds of paper can be traced through batches of bindings. Spier used waste paper with horizontal ink lines ( $B B$ f. 38r); Billingsley used pages from a Latin grammar (making it through most of the entries for 'A'). Wildegoose used a version of De Syllagismo (BB f. 33r); Johnson used a Latin text ( $B B$ f. 21r). Only a few of the pastedowns were interesting in themselves; $8^{\circ}$ B 105 Art. includes maps of the Holy Land, $8^{\circ} \mathrm{T} 42 \mathrm{Th}$. uses manuscript music waste in the spine, and a number of Wildegoose's bindings - including the First Folio mentioned above - use a pre-1500 printing of Cicero's De Officiis ( $B B$ f. 45r).

Inscriptions and labels generally revealed little, with the exception of Billingsley's regular autograph - "Richard Billingsley bound this booke" ( $B B$ f. 42v) - and conservators' notes. The usual superseded shelfmarks appear on the text block or spine of most volumes. Pasted labels are regular but not invariable. Shelfmarks are often written on the flyleaf, as is common in the Bodleian. One item $\left(8^{\circ}\right.$ B 105 Art.) had been lent out, against usual Bodleian practice, and contained the inscription "Me. Christ borrowed this Booke and delivered it again with his owne hand. 1640 J.W."

Although at least one copy of each text nearly always existed in the Library, it became clear that others had sometimes replaced them. Further comparison may indicate whether new copies were in better condition or contained notable elements; it is possible that copies donated by benefactors replaced originals in order to maintain complete collections. Some items noted as bound together in the $B B$ now appear bound with newer items under new shelfmarks; further investigation will be needed to determine the reasons.

\subsection{Summary}

The bindings matched to $B B$ entries generally conform to what one would expect of early seventeenthcentury Oxford bindings. So what does this information reveal about bindings, about the Bodleian? Compiling information en masse is one of the best ways to develop a picture of the situation; Pearson says, "Two thousand bindings, briefly described to a level of detail which will at least allow anyone interested to identify what is worth calling up, will probably be more useful to more people than two hundred bindings described in greater detail" (2005); as Ker concurs, "there is great virtue in numbers" (2004). This pilot did not allow the description of two thousand bindings, or even two hundred, but it provided the foundation upon which to continue - one that will provide information for qualitative as well as statistical analysis. The project was not designed to record every detail; rather, it helped generate a 'big picture' concept of bindings at Oxford with enough detail to flag patterns and items of interest. It was able to determine key features of various Oxford binders, establish a methodology and develop a way to present findings in a publicly accessible format.

\section{Conclusions}

This project has continued Oxford's tradition of researching and documenting bindings. It has demonstrated that an open-source standard with its origins outside the library environment (TEI) can provide a useful, appropriate, and extensible framework for library-based bindings documentation, and it joins a growing list of heritage projects that make use of TEI (www.tei-c.org/Activities/Projects).

Framing this research as a solo-person project undertaken for a graduate degree allowed for the exploration of both bindings terminology and markup language to find the most useful for the form and content of the $B B$ itself. The researcher was able to step outside the constraints of an existing library management system and encoding standard (MARC) and think about the scholarly concerns of analytical and descriptive bibliography: how could the entries in the $B B$ best be represented? She was able to consider specialist users with an interest in Oxford bindings, and to build a resource with their needs in mind. At the end of the pilot, bringing the BB in TEI within the institutional walls (the current and next phases of the work), questions focus on the advantages and disadvantages of harvesting data from the $B B$ in TEI for inclusion in the new library management system, or using a different way to link between the two resources. As discussed earlier, TEI's extensible nature opens a range of possibility for data sharing and representation. 
Finally, the existence of the $B B$ in TEI renders it compatible not solely with Bodleian resources, but with other bindings resources, should this be seen to be mutually beneficial by the projects' leaders. Certainly, for the wider community of rare book librarians, conservators and bibliographers interested in bindings information, provenance and book history, the development of a single search facility for the growing number of bindings resources online would be welcome.

\section{References}

Bauman, S. \& Catapano, T. (1999), "TEI and the encoding of the physical structure of books", Computers and the Humanities, Vol. 33, No. 1/2: Selected Papers from TEI 10: Celebrating the Tenth Anniversary of the Text Encoding Initiative, Apr. 1999, pp. 113-127, available at: http://www.jstor.org/stable/30200491 (accessed 12 June 2012).

Bibliographic Standards Committee of the Rare Books and Manuscripts Section (ACRL/ALA) (1988), Binding Evidence: A Thesaurus for Use in Rare Book and Special Collections Cataloguing, Association of College and Research Libraries, Chicago, available at:

http://www.rbms.info/committees/bibliographic standards/controlled vocabularies/introduc tions/BindingIntro.htm (accessed 12 June 2012).

Bibliographic Standards Committee of the Rare Books and Manuscripts Section (ACRL/ALA) with the Library of Congress (2007), Descriptive Cataloging of Rare Materials (Books), Cataloging Distribution Service, Library of Congress, Washington, D.C.

Binder's Book (1621-24) [BB], Bodleian Library: MS Library Records e.528.

Bodleian Library (1964), William Shakespeare: 1564-1964: A Catalogue of the Quatercentenary Exhibition in the Divinity School, Oxford, Bodleian Library, Oxford.

Bodley, T. (1703), Reliquice Bodleiana: or some genuine remains of Sir Thomas Bodley. Containing his life, the first draught of the statutes of the Publick library at Oxford, (in English) and a collection of letters to Dr. James, \&c., published from the originals in the said library, London, Eighteenth Century Collections Online, available at:

http://ezproxy.ouls.ox.ac.uk:2138/ecco/infomark.do?\&source=gale\&prodId=ECCO\&userGr oupName $=$ oxford $\&$ tabID $=$ T001\&docId $=C W 101122460 \&$ type $=$ multipage\&contentSet $=E C C$ OArticles\&version=1.0\&docLevel=FASCIMILE (accessed 12 June 2012).

Brassington, W.S. (1891), Historic Bindings in the Bodleian Library, Oxford, Sampson Low, Marston and Co., London.

Brassington, W.S. (1894), A History of the Art of Bookbinding, Eliot Stock, London.

British Census Project \& Sheppard, J. (ed.) (1997), A Guide to the Census of Western Medieval Bookbinding Structures to 1500 in British Libraries, n.p.

Coates, A., et al. (2005), A Catalogue of Books Printed in the Fifteenth Century now in the Bodleian Library, Oxford, Oxford University Press., Oxford, available at: http://www.bodleian.ox.ac.uk/bodley/library/specialcollections/rarebooks/bodleian incunabl e catalogue (accessed 12 June 2012).

Craster, H.H.E. (1952), History of the Bodleian Library, 1845-1945, Clarendon Press, Oxford.

Dawson, G. \& Kennedy-Skipton, L. (1968), Elizabethan Handwriting 1500-1650: A

Guide to the Reading of Documents and Manuscripts, Faber, London. 
DeRose, S. et al. (1990), "What is text, really?” Journal of Computing in Higher Education, Vol. 1, No. 2, Winter, pp. 3-26.

Digital Preservation Europe (2006-2007), "Istituto centrale per la patologia del libro, Italy: Census of Medieval Bindings", available at: http://www.digitalpreservationeurope.eu/competencecentres/list/?id=70 (accessed 12 June 2012).

Dondi, C. (2011), [Interview], Bodleian Library with the author, 29 June.

Drucker, J. (2009), SpecLab: Digital Aesthetics and Projects in Speculative Computing, University of Chicago Press, Chicago.

Folger Shakespeare Library (2012), Folger Binding Images Collection, available at http://www.folger.edu/template.cfm?cid=4147 (accessed 17 August 2012).

Getty Research Institute (2000), The Getty Art and Architecture Thesaurus Online, J. Paul Getty Trust, available at: http://www.getty.edu/research/tools/vocabularies/aat/ (accessed 12 June 2012).

Gibson, S. (1900-), Manuscript notes on bindings, Bodleian Library: Ms. Top Oxon c. 153.

Gibson, S. (1901-04), Some Notable Bodleian Bindings: 12th-18 Centuries, Oxford University Press, Oxford.

Gibson, S. (1903), Early Oxford Bindings, Oxford Bibliographical Society, Oxford University Press, Oxford.

Gibson, S. (1907), Abstracts from the Wills and Testamentary Documents of Binders, Printers, and Stationers of Oxford, from 1493-1638, Printed for the Bibliographical Society by Blades, East and Blades, London.

Goldfinch, J. (2011), "Database of Bookbindings, British Library", paper presented at The Place of Bindings Conference, 9 June 2011, Merton College, Oxford.

Harvey, PDA (2001), Editing Historical Records, British Library, London.

Hector, L.C. (1980), The Handwriting of English Documents, Kohler and Coombes, Dorking.

Hobson, G. (1929a), Bindings in Cambridge Libraries, Cambridge University Press, Cambridge.

Hobson, G. (1929b), English Binding Before 1500, Cambridge University Press, Cambridge.

Hockey, S. (2000), Electronic Texts in the Humanities, Oxford University Press, New York.

Ker, N. (2004), Fragments of Medieval Manuscripts Used as Pastedowns in Oxford Bindings (with a Survey of Oxford Binding c. 1515-1620), Oxford Bibliographical Society, Oxford.

Kirschenbaum, M. (2010), "What is digital humanities and what's it doing in English departments?" ADE Bulletin, 150, available at: http://mkirschenbaum.files.wordpress.com/2011/01/kirschenbaum ade150.pdf (accessed 12 June 2012).

Lavagnino, J. (2006), “When not to use TEI”, Burnard, L., O’Keeffe, K. \& Unsworth, J. (eds.), Electronic Textual Editing, MLA, New York, pp. 334-38. 
Ligatus (n.d.a), Bookbinding glossary: an English/Greek terminology for the structures and materials of Byzantine and Greek bookbinding [project page], available at: http://www.ligatus.org.uk/glossary (accessed 12 June 2012).

Ligatus (n.d.b). Saint Catherine's project [project page], available at: http://www.ligatus.org.uk/stcatherines (accessed 12 June 2012).

McGann, J. (2001), Radiant Textuality: Literature After the World Wide Web, Palgrave Macmillan, New York.

Macray, W. (1890), Annals of the Bodleian Library, Oxford: With a Notice of the Earlier Library of the University [personal copy interleaved with notes], Clarendon Press, Oxford, Bodleian Library: MS Lib. Records D. 1848.

Madan, F. (1895), The Early Oxford Press: A Bibliography of Printing and Publishing at Oxford, 1468-1640, Oxford Historical Society, Oxford.

Middleton, B. (1996), A History of English Craft Bookbinding Technique, The Holland Press, London.

Miller, J. (2010), Books Will Speak Plain: A Handbook for Identifying and Describing Historical Bindings, Legacy Press, Ann Arbor, Michigan.

Nixon, H. and Foot, M. (1992), The History of Decorated Bookbinding in England, Clarendon Press, Oxford.

Oldham, J. (1952), English Blind-Stamped Bindings, Cambridge University Press, Cambridge.

Parkes, M.B. (1979), English Cursive Book Hands 1250-1500, Scolar Press, London.

Parkes, M.B. (2008), Their Hands Before Our Eyes, Ashgate, Aldershot.

Pearson, D. (2005), English Bookbinding Styles 1450-1800: A Handbook, British Library and Oak Knoll Press, London.

Petti, A.G. (1977), English Literary Hands from Chaucer to Dryden, Edward Arnold, London.

Pickwoad, N. (2004), Assessment Manual: A Guide to the Survey Forms to Be Used in St Catherine's Monastery, n.p., available at:

http://www.ligatus.org.uk/sites/default/files/manual20050110.pdf (accessed 12 June 2012).

Philip, I.G. (1983), The Bodleian Library in the Seventeenth and Eighteenth Centuries, Lyell Lectures, Clarendon Press, Oxford.

Pollard, G., ed. (1955), The Earliest Directory of the Book Trade, The Bibliographical Society, London.

ProBok (n.d.), ProBok: a database of provenance and bindings [brochure], Lund University and Uppsala University.

ProBok (2010-2011), “The ProBok project”, Lund University and Uppsala University, available at: http://www.probok.se/probokEn.jsf (accessed 12 June 2012).

Renear, A. (1997), "Out of praxis: three (meta)theories of textuality", Sutherland, K. (ed.), Electronic Text: Investigations in Method and Theory, Clarendon Press, Oxford, pp. 107-26. 
Renear, A., Mylonas, E. \& Durand, D. (1996), "Refining our notion of what text really is." Ide, N. \& Hockey, S. (eds.), Research in Humanities Computing 4, Clarendon Press, Oxford, available at: http://www.stg.brown.edu/resources/stg/monographs/ohco.html (accessed 12 June 2012).

Roberts, M., \& Etherington, D. (1982), Bookbinding and the Conservation of Books: A Dictionary of Descriptive Terminology, Library of Congress, Washington, D.C., available at: http://cool.conservationus.org/don// (accessed 12 June 2012).

Schmidt, D. (2010), "The inadequacy of embedded markup for cultural heritage texts", Literary \& Linguistic Computing, Vol. 25, No. 3, available at: http://dx.doi.org/10.1093/llc/fqq007 (accessed 12 June 2012).

TEI@Oxford (2010), “TEI and manuscript description for WACMP”, PowerPoint presentations given February 2010, Oxford, available at: http://tei.oucs.ox.ac.uk/Talks/2010-02-0405-cambridge/ (accessed 12 June 2012).

TEI@Oxford (2011), “Getting started with TEI”, last modified 7 March 2011, available at: http://tei.oucs.ox.ac.uk/GettingStarted/html/in.html (accessed 12 June 2012).

TEI Consortium Libraries Special Interest Group (SIG) and the Digital Library Foundation-sponsored TEI Task Force (2009), "Best practices for TEI in libraries", version 3, available at: http://purl.oclc.org/NET/teiinlibraries (accessed 12 June 2012).

Velios, A. (2011), “The Ligatus glossary project," paper presented at The Place of Bindings Conference, 9 June 2011, Merton College, Oxford.

Wheeler, G.W., ed. (1926), Letters of Sir Thomas Bodley to Thomas James, Clarendon Press, Oxford.

Wisneski, R. and Dressler, V. (2009), "Implementing TEI projects and accompanying metadata for small libraries: rationale and best practices", Journal of Library Metadata, Vol. 9, No. 3, pp. 264-88.

Wittenburg, A. (2011), "Einbanddatenbank", paper presented at The Place of Bindings Conference, 9 June 2011, Merton College, Oxford.

\section{About the authors}

Elizabeth McCarthy is Communications and Social Media Officer for the Bodleian Libraries as well as an assistant in the Bodleian's Conservative Party Archives. In addition to her focus on outreach and digital communications in libraries, she maintains a research interest in library history, bindings and historical bibliography. Elizabeth McCarthy is the corresponding author and can be contacted at: elizabeth.mccarthy@,bodleian.ox.ac.uk.

Anne Welsh is Lecturer in Library and Information Studies at University College London and Digital Identity Manager of the UCL Centre for Digital Humanities. Her research and teaching is centred on Cataloguing and Historical Bibliography. She is the lead author of Practical Cataloguing: AACR, RDA and MARC 21 (Facet, 2012) and has chapters in press for Digital Humanities in Practice (Facet, 2012) and Ambassadors of the Booke (De Gruyter, 2012).

Sarah Wheale has been a curator of Rare Books at the Bodleian Library since 2002, with responsibility for a broad range of projects in addition to day-to-day work within the section. 